\title{
Asbestos related diseases from environmental exposure to crocidolite in Da-yao, China. I. Review of exposure and epidemiological data
}

\author{
S Luo, X Liu, S Mu, S P Tsai, C P Wen
}

Occup Environ Med 2003;60:35-42

\begin{abstract}
Background: Scattered patches of crocidolite, one form of asbestos, were found in the surface soil in the rural county of Da-yao in southwestern China. In 1983, researchers from the West China University of Medical Sciences (WCUMS) discovered that residents of two villages in Da-yao had hyperendemic pleural plaques and excessive numbers of pleural mesotheliomas.

Aims: To review and summarise epidemiological studies, along with other relevant data, and to discuss the potential contribution to environmental risk assessment.

Methods: This report is based on a review of several clinical/epidemiological studies conducted by WCUMS researchers since 1984, which included one cross sectional medical examination survey, one clinical/pathological analysis of 46 cases of mesothelioma, and three retrospective cohort mortality studies. Additional information acquired from reviewing original data first hand during a personal visit along with an interview of medical specialists from Da-yao County Hospital was also incorporated.

Results: The prevalence of pleural plaque was 20\% among peasants in Da-yao over 40 years of age in the cross sectional survey. The average number of mesothelioma cases was 6.6 per year in the 1984-95 period and 22 per year in the 1996-99 period, in a population of 68000 . For those mesothelioma cases that were histology confirmed, there were 3.8 cases/year in the first period and 9 cases/year in the second. Of the 2175 peasants in this survey, 16 had asbestosis. Lung cancer deaths were significantly increased in all three cohort studies. The annual mortality rate for mesothelioma was 85 per million, 178 per million, and 365 per million for the three cohort studies, respectively. The higher exposed peasants had a fivefold increased mesothelioma mortality compared to their lower exposed counterparts. There were no cases of mesothelioma in the comparison groups where no crocidolite was known to exist in the environment. In the third cohort study, almost one of five cancer deaths $(22 \%)$ was from mesothelioma. The ratio of lung cancer to mesothelioma deaths was low for all three studies (1.3, 3.0, and 1.2, respectively). Conclusions: The observation of numerous mesothelioma cases at Da-yao was a unique finding, due mainly to their lifetime exposure to crocidolite asbestos. The finding of cases dying at a younger age and the relatively high ratio of mesothelioma cases to lung cancer could also be another unique result of lifetime environmental exposure to crocidolite asbestos. Although the commercial use of crocidolite has been officially banned since 1984, the incidence of mesothelioma has continued to show a steady increase, particularly among peasants. Since the latency of mesothelioma is approximately 30-40 years, the ban had little effect in the 1990s. The increased awareness and changes in diagnosis over time may also contribute to the increase. Furthermore, exposure to asbestos stoves and walls continued. The government implemented reduction of these exposures. However, from a public health standpoint, the most important issue is the complete avoidance of further exposure to asbestos.
\end{abstract}

See end of article for authors' affiliations

Correspondence to: Dr C P Wen, 2F, 109 Min-Chuan East Road,' Sec. 6, Taipei 114, Taiwan, ROC:

cwengood@aol.com/ cwengood@nhri.org.tw

Accepted

13 February 2002
$\mathrm{D}$ a-yao, an isolated, underdeveloped county town with a total population around 280000 , is located in the mountainous province of Yunnan in the most southwestern part of China. The climate in Da-yao is spring-like year round, and the majority of inhabitants are peasants. This rural town has been relatively isolated from the outside world because of its remoteness, its poverty, and poor road access. The nearest major city is a four hour bumpy bus ride away. The stable population has had virtually no influx of out-of-towners. The annual per capita income in Da-yao is about US\$300, and for the peasants could be less than half of that, depending on the harvest of tobacco. The smoking prevalence in Da-yao is very high among adult males, about 80\% (Local Health Department, 1997; personal communication), compared to $63 \%$ in the corresponding general population"; this is primarily because of the ready availability of cigarettes since Yunnan is a major tobacco producing province in China.
The county seat of Da-yao is located in Jin-bi village. The land in Jin-bi and its two neighbouring villages (Huang-haitun and Shi-yang), nearly 200 square kilometres, is covered with naturally scattered patches of superficial, bluish clay-like crocidolite ore, which is called "blue clay" by the local people. The population of the three villages is about 68000 . The patches of blue clay tend to appear in clusters and occur sporadically to cover only about $20 \%$ of the total ground surface of these three villages. The blue clay is friable, easily broken by hand and slowly dissolvable by rainwater. In contrast to other types of asbestos fibres, the crocidolite fibres from Da-yao are short and rigid, and, as a result, their industrial uses have been

Abbreviations: IARC, International Agency Research on Cancer; SMR, standardised mortality ratio; UICC, Union Internationale Contre le Cancer; WCUMS, West China University of Medical Sciences 
limited. On a dry and windy day, the disintegrated blue clay is often blown into the air and forms fine dust particles. This is particularly so in recent years when potholes of unpaved roads, the major avenue of transportation, have been filled with this blue clay from the nearby hills, containing various concentrations of crocidolite. The entire population, including small children, has thus been exposed to this asbestos containing clay dust every day. Children walk along the unpaved road to and from school, inhaling high levels of dust from motorised vehicles passing by. Smaller kids used to sit and play on piles of asbestos ore. Thus, the rural residents in the three villages of Da-yao, young and old, have been breathing an atmosphere contaminated with asbestos fibres. In the town centre of the Jin-bi, on the other hand, widespread cement pavement has eliminated much of this type of exposure.

Because of its blue colour, peasants have also used this crocidolite containing clay as stucco for plastering their houses or painting the walls (about $60 \%$ of the 976 families investigated in 1984 did so). In addition, occupational exposure occurred when some peasants tried to make commercial products out of the crocidolite ore, by crushing the ore either by machine or by hand and making asbestos stoves and stove tubes in a semi-open air environment. As many as 300000 stoves were made annually by the family styled production during the peak years of the early 1980s. Some of these stoves were consumed locally, but most were sold elsewhere. Because of the health risk of asbestos publicised by the West China University of Medical Sciences (WCUMS) research team, this practice was officially banned in 1984. The market has drastically tapered off since then, although some residual usage remains, albeit at a much lesser degree and behind closed doors.

In 1983, researchers from WCUMS found several cases of pleural plaques and mesothelioma among residents of two rural villages (Jin-Bi and Huang-hai-tun) in Da-yao. Since then, they have conducted a series of studies. ${ }^{2-7}$ The purpose of this paper is to summarise and review these studies, with most of them not hitherto made available to the English speaking scientific community, and discuss the unique health experience of the residents with their environmental asbestos exposure.

\section{EXPOSURE DATA}

The soil (blue clay) was collected, and the composition of the fibres was analysed using energy dispersive $x$ ray analysis and scanning electron microscopy. The main chemical composition of Da-yao crocidolite is ferromagnesian minerals. The energy dispersive $x$ ray analysis showed that all samples contained relatively high levels of $\mathrm{Fe}$ and $\mathrm{Na}$, similar to that of UICC (Union Internationale Contre le Cancer) crocidolite. ${ }^{3}$ The high component of iron is characteristic of crocidolite. The percentages of $\mathrm{Fe}$ and $\mathrm{Na}$ element in the crocidolite ore from Da-yao (33.6\% and $4.1 \%$, respectively) were virtually the same as those from Cape Province of South Africa (37.4\% and 6.2\%) and from Australia (33.5\% and 6.0\%, respectively). However, the corresponding elements for chrysotile from Quebec were present at $1.5 \%$ and $0.1 \%$, respectively. ${ }^{8}$

Through weathering and scouring, the crocidolite ore was easily loosened and the eroded surface became a natural source of air contamination. In addition, because of widespread practice of digging in the hilltop of the blue clay by private individuals and/or commercial excavation, the earth's protective surface, such as trees or grass, had been partially destroyed, resulting in serious soil erosion. Thus, the atmosphere, the water supply, and the soil in Da-yao are all grossly contaminated with asbestos. Even the pits, pools, and ponds were polluted and the water became greenish in colour, especially after a heavy rain. In addition, on average, every family used one or two asbestos stoves in the home. The stove would normally last for 1-2 years, but most peasants would try to extend its lifespan to $3-5$ years by fixing the disintegrating structure when worn with metal wire. The surfaces of the stoves and stove tubes were easily loosened during the repeated wet and dry cycle, and residents had opportunities of exposure, although minimal, to asbestos fibres when fanning the stove. Non-functional stove units were discarded in the open fields and created another source of contamination to the environment.

In the production of clay stoves, some were mechanised in a larger operation, while some still resorted to primitive manual labour. Approximately $40 \%$ of the raw ore was crushed by hand and the remaining $60 \%$ by machine, which can generate a plume of dust in the enclosed room. The asbestos concentration in the mechanised ore crusher room has been analysed. ${ }^{3}$ The dust concentration in the air ranged from 47 to $413 \mathrm{mg} / \mathrm{m}^{3}$, with an average concentration of $187 \mathrm{mg} / \mathrm{m}^{3}$, at 2 metres distance from the crushing machine. The dust concentration diminished to an average of $13 \mathrm{mg} / \mathrm{m}^{3}$ (range 5-28 $\mathrm{mg} / \mathrm{m}^{3}$ ) at 8 metres from the machine. The concentration at 20 metres from the crusher room averaged $1.8 \mathrm{mg} / \mathrm{m}^{3}$, more than 10 times the official hygienic standard of China $\left(0.15 \mathrm{mg} / \mathrm{m}^{3}\right)$.

Fibres were counted using an Olympus contrast microscope (at a magnification of 500), based on the AIA method. ${ }^{9}$ In 1985 , the average fibre count in the crusher room was $6.6 \mathrm{f} / \mathrm{cm}^{3}$ with a peak of $25.4 \mathrm{f} / \mathrm{cm}^{3}$, far exceeding the threshold limit value of 0.1 or $0.2 \mathrm{f} / \mathrm{cm}^{3} .{ }^{10}$ More than $80 \%$ of the airborne asbestos fibres were $5-20 \mu \mathrm{m}$ in length, and most were less than $3 \mu \mathrm{m}$ in diameter.

\section{PREVALENCE OF PLEURAL PLAQUES}

Peasants from the two villages (Jin-bi and Huang-hai-tun) were investigated, based on a cross sectional survey conducted in $1984 .{ }^{2}{ }^{3}$ For logistic reasons, Shi-yang was not included in this survey and the subsequent cohort mortality studies. Asbestos stoves were used exclusively for decades in these two villages, and some peasants also engaged in asbestos stove production. Townships with the earliest asbestos stove production within these two villages were selected. A total of 2175 adults (996 men, 1179 women), 20 years of age and older who were born and raised in these two villages were identified. More than half $(53 \%$ of the men and $54 \%$ of the women) were over 40 years of age. Everyone was given a physical examination and chest fluoroscopy; for suspicious cases, a chest $x$ ray was offered. In addition, those over 40 years of age were given chest radiograms regardless of the fluoroscopic screening results. Similar examinations were also provided to 1338 peasants serving as the comparison group. These peasants for comparison were selected from those 20 years and older living closest (230 kilometres southwest) to the two villages, with similar living conditions but without asbestos fibre contamination. The comparison group was similar to the study group in gender distribution (46\% males) but was slightly younger (average of 37 years of age in comparison group versus 43 years in the study group). Smoking data for the two groups were also similar (Local Health Department, 1997; personal communication).

Pleural plaques were identified, using ILO classification criteria, in 232 of the 2175 cases examined in the study group, yielding a prevalence rate of $11 \%$. Among those over 40 years of age, the prevalence rose to $20 \%$. Pleural plaques are a recognised biomarker of previous exposure to asbestos. Most of the plaques were calcified and located more in the lateral chest wall than in the posterior-anterior chest wall. The shapes of the pleural plaques varied, with more serious cases showing a map-like pattern. The pleural plaques found in the pericardium and the mediastinum took the shape of straight lines, resulting in a stiff appearance to the pericardium and diaphragm. In addition to these asymptomatic pleural plaques, 16 peasants had full blown asbestosis, yielding a prevalence rate of $1.4 \%$ among those over 40 years of age. The 
false negativity rate of chest fluoroscopy was unknown. No one was found to have pleural plaques or asbestosis in the comparison group.

\section{PATHOLOGICAL REVIEW OF MESOTHELIOMA CASES \\ Period I: 1984-95}

Based on a review of Da-yao county hospital records for the 12 year period from 1984 to 1995 , Zhou et al identified a total of 79 cases of mesothelioma. ${ }^{6}$ These cases came mainly from the Jin-bi village, where the county hospital is located, and a few others from the other two neighbouring villages, with a combined total population of 68000 . This is equivalent to an incidence rate of 97 cases/million/year for mesothelioma. Because there were known cases of mesothelioma living in these three villages that were treated at a major medical centre 320 kilometres away, the true incidence should have been higher. On the other hand, some of these 79 patients came from villages other than these three in this county. The population of the entire county is about 280000 , yielding an estimated incidence rate of approximately 24 cases/million/year for the county. Of the 79 cases, 46 had been confirmed as mesothelioma. Among these, 28 cases were diagnosed by biopsy, four by postmortem examination, and two by electron microscopy. The remaining 12 cases were submitted to a panel of specialists from the University Cancer Research Center of WCUMS for review. Based on the clinical or histological material, these cases were confirmed to be mesothelioma. The 33 unconfirmed cases were diagnosed through $x$ ray and clinical observation since patients refused the biopsy for various reasons.

Of the 46 confirmed cases of mesothelioma, there were 36 cases of pleural origin, eight cases of peritoneal origin, one case of pleural/peritoneal mixed origin, and one case of benign peritoneal mesothelioma. The ratio of pleural to peritoneal origin was about 4 to 1 , predominantly pleural. Age at death ranged from 20 to 75 years of age with an average of 55 years, which is younger than mesothelioma cases seen in occupationally exposed populations. Twenty eight cases were men and 18 were women. The survival time from the time of diagnosis was very short and mostly less than a year: $3-11$ months for pleural cases and 4-14 months for peritoneal cases. This reflected the late stage diagnosis for most of the cases, inadequate care, and high case fatality of this cancer. The only exception was the benign peritoneal case, which relapsed four years after the tumour $(20 \mathrm{~cm} \times 18 \mathrm{~cm} \times 18 \mathrm{~cm})$ was removed. A second surgical procedure was performed, and this patient is still alive two years later.

\section{Period II: 1996-99}

Another 87 cases of mesothelioma have been registered in the hospital records during a four year period from 1996 to 1999. Among them, 37 cases were histologically confirmed on specimens either from biopsy (33 cases) or from autopsy (four cases). The male/female sex distribution was $27: 10$, and the average age at death was 56 years. In the remaining 50 cases, 19 were diagnosed by cell cytology from pleural or peritoneal fluid and nine by computed tomography scan. As rare as mesothelioma can be in most parts of the world, there happened to be a sibling cluster in Da-yao. A 41 year old brother was recently diagnosed with this condition, while his sister had died from mesothelioma at the age of 24 years. They shared similar exposure risks, but the extent of genetic influence remains to be elucidated.

\section{FOLLOW UP MORTALITY STUDIES}

Three retrospective cohort mortality studies were conducted in different time periods.

\section{Study I}

The first study included a cohort of 5603 adults who were born from 1915 to $1955 .^{23}$ All lived in the two villages within Da-yao for most of their lives, where the surface soil has contained crocidolite or blue clay. This particular age group was chosen because those born before 1915 would have been very difficult to trace and those born after 1955 have not had much risk of death. A cluster random sampling method was employed. Village subunits, including residences and worksites, were randomly selected and all subjects meeting study cohort criteria were included and followed for seven years from l January 1977 to 31 December 1983. Vital status or verification of the date of death of the study subject was established by contacting the subject or a member of his/her close family by telephone, mail, or home visits. Among decedents, a copy of the death record from the hospital was obtained. For those patients who had no hospital records, the patients' physicians were contacted and interviewed. Unconfirmed cancer cases where no hospital records could be ascertained were treated as unknown cause. Causes of death were classified according to the 9th revision of the International Classification of Diseases. At the end of this process, vital status for about $10 \%$ of the study subjects could not be identified, and their vital status was treated as unknown. The only appropriate data set available for comparison was the cancer survey data from 1974 to 1976 , collected by local prefecture from the neighbouring counties (in the state of Chu Xiong) without crocidolite contamination. The size of the comparison population was more than 10 times larger than that of the study cohort.

All cause mortality was about $40 \%$ lower than expected (139 observed and 236 expected deaths, standardised mortality ratio $(S M R)=0.59)$. Overall cancer was a third higher than the comparison group, with an age and sex adjusted SMR of 1.34 (25 observed and 18.6 expected deaths). There were significantly fewer deaths caused by non-malignant diseases ( SMR $=0.53$ ). Lung cancer, excluding mesothelioma, was sevenfold higher (four observed deaths, SMR $=6.67$ ) than in the comparison group. The average age of death for lung cancer was 45 years. Stomach cancer mortality was about the same as expected ( 4 observed $v 3.7$ expected). There were three cases of mesothelioma. This yielded an average annual mortality rate of 85 per million, substantially higher than that for the general population in North America or western European countries, where the rate was $1-3$ cases per million among women and 5-15 per million among men during the similar time period. ${ }^{11}$

\section{Study II}

The second study was a nine year (1987 to 1995) retrospective mortality follow up of 4598 Da-yao residents (2764 men and 1834 women) aged 30 years or older as of 1 January $1987 .{ }^{5}$ The study design was similar to that of the first study. A local census was used to select the study population based on a cluster random sampling method, and peasants accounted for about $40 \%$. Using the same method, the comparison group $(\mathrm{n}=5641)$ was chosen from residents who lived in another town approximately 200 kilometres from Da-yao, where no asbestos was found in the environment. The comparison group had similar gender composition $(60 \%$ men in the study group and 55\% in the comparison group), and similar smoking prevalence (Local Health Department, 1997; personal communication). Because of the inclusion criteria for age, the age distributions were virtually the same for the two groups. ${ }^{5}$

For both the study and comparison groups, a person entered follow up on 1 January 1987 if he or she was 30 years or older on that date. Otherwise, the subject entered follow up on his or her 30th birthday. Vital status as of 31 December 1995 for each subject from both the study and comparison groups was determined from a number of sources similar to those used by 
Table 1 Observed deaths and crude mortality rate for the study and comparison groups-cohort II

\begin{tabular}{|c|c|c|c|c|}
\hline \multirow[b]{2}{*}{ Cause of death } & \multicolumn{2}{|l|}{ Study group } & \multicolumn{2}{|c|}{ Comparison group } \\
\hline & $\begin{array}{l}\text { Number of } \\
\text { deaths }\end{array}$ & $\begin{array}{l}\text { Crude death rate } \\
\left(1 / 10^{5}\right)\end{array}$ & $\begin{array}{l}\text { Number of } \\
\text { deaths }\end{array}$ & $\begin{array}{l}\text { Crude death rate } \\
\left(1 / 10^{5}\right)\end{array}$ \\
\hline All causes & 397 & 1006.9 & 520 & 1078.0 \\
\hline All malignant neoplasms & 72 & 182.6 & 60 & 124.4 \\
\hline Lung & 21 & 53.3 & 12 & 24.9 \\
\hline Mesothelioma & 7 & 17.8 & 0 & - \\
\hline Liver & 15 & 38.0 & 14 & 29.0 \\
\hline Stomach & 6 & 15.2 & 9 & 18.7 \\
\hline Bowel & 6 & 15.2 & 3 & 6.2 \\
\hline Nasopharynx & 4 & 10.1 & 5 & 10.4 \\
\hline Oesophagus & 3 & 7.6 & 3 & 6.2 \\
\hline Breast & 3 & 7.6 & 3 & 6.2 \\
\hline Cervix & 2 & 5.1 & 0 & - \\
\hline Lymphoma & 2 & 5.1 & 2 & 4.2 \\
\hline Leukaemia & 1 & 2.5 & 3 & 6.2 \\
\hline All others & 2 & 5.1 & 6 & 12.4 \\
\hline Infectious disease & 6 & 15.2 & 8 & 16.6 \\
\hline Circulatory disease & 167 & 423.5 & 250 & 518.3 \\
\hline Respiratory disease & 14 & 35.5 & 42 & 87.1 \\
\hline Digestive disease & 17 & 43.1 & 23 & 47.7 \\
\hline Injury and poisoning & 28 & 71.0 & 38 & 78.8 \\
\hline Unknown & 64 & 162.3 & 74 & 153.4 \\
\hline Other disease & 29 & 73.6 & 25 & 51.8 \\
\hline
\end{tabular}

study I. The lost to follow up rate was less than $1.5 \%$ for both groups. The total person-years were 39430 and 48236 for the study and comparison groups, respectively.

Table 1 presents the observed numbers of deaths and the crude mortality rate for the study and comparison groups. The mortality for all causes combined was slightly lower for the study than for the comparison group ( 1007 per $100000 v 1078$ per 100000$)$. The rate of overall cancer was $47 \%$ higher in the study group ( 182.6 per $100000 \vee 124.4$ per 100000 ), with 72 cancer deaths during the nine year follow up period. Rates for infectious diseases, injury and poisoning, and undefined causes were similar between the two groups. Unknown causes of death accounted for about $15 \%$ of the total number of deaths for both groups. The relatively large proportion of unknown causes of deaths is a common problem among rural populations in China. This is primarily because a large number of older persons ( 70 years and older) did not go to hospital and died at home.

There were 21 deaths from lung cancer in the study group. The lung cancer rate was significantly increased among the study subjects $(53.3$ per $100000 \vee 24.9$ per 100000 in the comparison), with a relative risk of 2.14 (95\% confidence interval: 1.07 to 4.28 ). The average age at death for the lung cancer cases was 59 years in the study group and 63 years in the comparison group. Seven cases of mesothelioma (177.5 per million/year) were identified in the exposed group while none were found in the comparison group. Four of the mesothelioma cases were diagnosed through postmortem

\begin{tabular}{|c|c|c|c|c|}
\hline \multirow[b]{2}{*}{ Cause of death } & Study group & & & \\
\hline & $\begin{array}{l}\text { Number of } \\
\text { deaths }\end{array}$ & $\begin{array}{l}\text { Crude death rate } \\
\left(1 / 10^{5}\right)\end{array}$ & $\begin{array}{l}\text { Number of } \\
\text { deaths }\end{array}$ & $\begin{array}{l}\text { Crude death rate } \\
\left(1 / 10^{5}\right)\end{array}$ \\
\hline All causes & 166 & 1210.5 & 339 & 1639.2 \\
\hline All malignant neoplasms & 23 & 167.7 & 19 & 91.9 \\
\hline Lung & 6 & 43.8 & 3 & 14.5 \\
\hline Mesothelioma & 5 & 36.5 & 0 & - \\
\hline Liver & 5 & 36.5 & 2 & 9.7 \\
\hline Stomach & 3 & 21.9 & 6 & 29.0 \\
\hline Bowel & 1 & 7.3 & 3 & 14.5 \\
\hline Nasopharynx & 0 & - & 1 & 4.8 \\
\hline Oesophagus & 0 & - & 2 & 9.7 \\
\hline Breast & 0 & - & 1 & 4.8 \\
\hline Cervix & 1 & 7.3 & 0 & - \\
\hline Lymphoma & 1 & 7.3 & 0 & - \\
\hline Leukaemia & 0 & - & 0 & - \\
\hline All others & 1 & 7.3 & 1 & 4.8 \\
\hline Infectious disease & 3 & 21.9 & 4 & 19.3 \\
\hline Circulatory disease & 71 & 517.7 & 191 & 923.6 \\
\hline Respiratory disease & 5 & 36.5 & 34 & 164.4 \\
\hline Digestive disease & 5 & 36.5 & 19 & 91.9 \\
\hline Injury and poisoning & 8 & 58.3 & 19 & 91.9 \\
\hline Unknown & 41 & 299.0 & 33 & 159.6 \\
\hline Other disease & 10 & 72.9 & 20 & 96.7 \\
\hline
\end{tabular}


examination and the other three through $x$ ray and computed tomography scan. The age at death for the seven mesothelioma cases ranged from 53 to 64 years. Results for stomach and colon cancers were not remarkable. The mortality rate was lower for stomach cancer but higher for colon cancer in the study group than the comparison group, although none of the differences were statistically significant.

\section{Study III}

The third study was a mortality follow up on a subset of study II. $^{7}$ Only peasants from study II were included in the analysis. The number of people included in the study group was 1610 and the comparison group, 2481. Since the populations for both groups were stable, the number lost to follow up was very low $(0.7 \%$ and $0.3 \%$, respectively). The age distributions of the two groups were almost identical. The total person-years of follow up were 13714 for the study group and 20681 for the comparison group.

The mortality for all causes combined for the study group was significantly lower than the comparison group (1210.5 per $100000 v 1639.2$ per 100 000; table 2). This was due mainly to a lower mortality rate from circulatory system disease (517.7 per $100000 v 923.6$ per 100000 ). The death rate from unknown causes for the study group was about twice that of the comparison group (299.0 per $100000 v 159.6$ per 100000$)$. Mortality for all cancer was significantly higher among peasants in the study group ( 167.7 per $100000 v 91.9$ per 100000 ). There were six deaths from lung cancer with a crude rate of 43.8 per 100000 , compared to 14.5 per 100000 in the comparison group (relative risk $=3.02$ ). Five cases of mesothelioma were observed in the study group while none was seen in the comparison group. Mesothelioma was the second leading cause of death from cancer and accounted for $22 \%$ of the total cancer deaths $(n=23$ deaths $)$.

\section{DISCUSSION}

The use of asbestos or exposure to asbestos has been increasing in economically developing China as the construction industry has been booming with dizzying speed. As in many other countries, the asbestos used for insulation in the industry was primarily chrysotile in China, but the extent to which other forms of asbestos were used in a vast country like China remains to be explored. In a comprehensive nationwide survey of pneumoconiosis data published in 1992, asbestosis among the Chinese has shown a stepwise increase in the past 30 years. ${ }^{12}$ By the late 1980 s, there were more than 4000 cases per year reported officially from occupational settings such as textile workers. However, as for environmental (nonoccupational) asbestos exposure or the use of crocidolite fibres in China, both had been rare and few had been reported in the literature outside China.

Asbestos has been classified by the International Agency Research on Cancer (IARC) as a group I carcinogen: known human carcinogen. ${ }^{13}$ Lung cancer, mesothelioma, and asbestosis have been most often associated with asbestos exposure ${ }^{14-20}$ with an average latency for cancer as long as 30-40 years. Cancers from other sites such as larynx, oesophagus, colon, and large intestine have also been reported. ${ }^{1721} 22$ All forms of asbestos are known to be carcinogenic, with chrysotile, crocidolite, amosite, and anthophyllite being commercially important. ${ }^{23} 24$

Residents of Da-yao have been exposed, knowingly or unknowingly, to crocidolite asbestos from the contaminated environment throughout their entire lifetime. The route of exposure should be mainly inhalation. Ingestion of asbestos containing water or dermal contact from manual handling or body exposure must be commonplace, but their health impact has not been studied. The crocidolite from Da-yao has been successfully used to induce pleural mesothelioma in rats at a rate similar to that of the UICC crocidolite. ${ }^{425}$ Since 1984, health studies in this community have shown higher than expected rates of pleural plaque, asbestosis, mesothelioma, and lung cancer. In contrast, there were no cases of pleural plaque, asbestosis, or mesothelioma in the comparison villages where no naturally occurring asbestos deposits were found.

Mortality from lung cancer was increased for all three cohort studies, with relative risks of $6.67,2.14$, and 3.02, respectively. Smoking is usually the main cause of lung cancer, particularly in Da-yao where $80 \%$ of adult males smoke (Local Health Department, 1997; personal communication). However, the observed excess of lung cancer is probably caused by crocidolite fibres since the smoking rates were similar between the study and comparison groups. We cannot discount the presence of well reported synergistic effects between smoking and asbestos, which may have also contributed to this excess. The third cohort study population included only peasants while the second study consisted of both peasants and non-peasants. This increased lung cancer mortality among peasants could be attributed to a higher level of daily exposure to crocidolite fibres among peasants.

The average number of mesothelioma cases at the county hospital continued to rise, from 6.6 per year during the period 1984-95 to 22 per year during the period 1996-99. The corresponding numbers for the histology confirmed cases were 3.8 per year and 9.3 per year, respectively. The mortality rate for mesothelioma between the first and second cohort studies has also increased. The average annual mortality rate for mesothelioma was 85 per million during the 1977-83 period. The rate doubled (to 178 per million) 10 years later during 1987-95. This could be a result of the latent effect of asbestos exposure. The fact that the second study population is about 10 years older may also be contributary. When the study was limited to include only peasants in the third study, the rate for mesothelioma rose to 365/million/year. The most striking observation in the third study is that the number of mesotheliomas was so large that it accounted for $22 \%$ of all cancer deaths. Furthermore, the crude rate ratio for mesothelioma between peasants and non-peasants (that is, the higher exposure group versus the lower exposure group) in the second study was 4.7 (365 per million/year $v 78$ per million/year), indicating a positive dose response relation for crocidolite exposure.

The association between mesothelioma and asbestos exposure has been well documented. The incidence of mesothelioma is extremely rare throughout the world. ${ }^{11}$ Its occurrence is even more rare in Asian populations. For example, in Japan with a population of 130 million, the number of deaths with mesothelioma recorded as the primary cause in the whole country was 111 in 1985, 163 in 1991, and 281 in $1997 .{ }^{26}$ If causes other than the primary were to be included, the number in 1997 was nearly $500 .{ }^{27}$ In Taiwan, with a population of 21 million, there were 12 deaths recorded as primary in 1997 or about 40 deaths to include secondary causes. ${ }^{28}$ The crude mortality rate for mesothelioma in Japan or Taiwan was no more than $2-3 /$ million/year. Similar rarity is expected in China. This is in contrast to western populations. For example, in the state of Texas with a population of approximately 20 million, there were 141 deaths from mesothelioma in 1995 , yielding a crude mortality rate of 7/million/year (Weiss, 1999, personal communication). Some researchers had proposed that Asians seemed to have a racial resistance to mesothelioma, but the problem could have been one of under diagnosis, ${ }^{29}$ because of its rarity and possible confusion over metastatic cancer of other origin to pleura. The high incidence of mesothelioma observed in studies of Da-yao residents clearly shows that the Chinese, given asbestos exposure for a sufficient length of time, can develop mesothelioma at a level comparable to or higher than that of the white population. It is noteworthy, however, that none of the mesothelioma cases included in Da-yao studies had a history of making asbestos stoves, which presumably had the greatest potential for asbestos exposure. This observation could be a result of the small 


\section{Main messages}

- Due to lifetime environmental exposure to crocidolite asbestos, residents in Da-yao had significantly higher than expected rates of pleural plaques, asbestosis, mesothelioma, and lung cancer.

- The prevalence of pleural plaques was $11 \%$ among residents 20 years and over and was $20 \%$ among those over 40 years of age, a reflection of significant asbestos exposure in the past.

- The annual mortality rate for mesothelioma ranged from 85 per million to 365 per million, compared to 2-3 per million in the general population.

- The ratio of lung cancer to mesothelioma was low (1.2-3.0) in this population, although the prevalence of smoking was as high as $80 \%$ among men.

number of stove production workers in these villages (less than 50); also, not all of them were included in the cohort because of the sampling methodology of these studies.

The relatively low ratio of lung cancer to mesothelioma deaths in the three cohort studies is noteworthy. This ratio in occupationally asbestos exposed workers (for example, insulators, shipyard workers) is generally in the range 3-4. ${ }^{17} 18$ In Da-yao, the ratio of lung cancer to mesothelioma was almost equal to one in two of the three cohort studies $(4 v 3$ in the first study and $6 v 5$ in the third study). In the second study, the ratio was 3.0 with 21 cases of lung cancer and seven cases of mesothelioma. The low ratio of lung cancer to mesothelioma is probably a result of the unique nature of asbestos exposure among villagers in that all study subjects were exposed to crocidolite fibres from birth, and the exposure lasted throughout their lifetime. Similar observations of a low ratio of lung cancer to mesothelioma have been reported by others in occupationally exposed groups when the asbestos exposure occurred at very young ages ${ }^{30}{ }^{31}$ and in crocidolite exposed workers. ${ }^{32}$

The number of deaths from asbestosis was also of interest. It is generally recognised that the level of asbestosis is indicative of both the intensity and the duration of asbestos exposure. ${ }^{15}$ In Da-yao, 16 cases of asbestosis were found in the cross sectional study of 2175 adults. Unfortunately, because of the lack of funding, asbestosis was not evaluated in the cohort studies.

Similar relations between environmental exposure to asbestos and mesothelioma have been reported in studies of South Africa ${ }^{334}$ and Western Australia ${ }^{35}$ crocidolite mining districts, and of several villages in Turkey. ${ }^{36}$ Mortality rates in South Africa crocidolite districts were increased for asbestosis, mesothelioma, and cancer of the lung and stomach. In Wittenoom, Australia, about $20 \%$ of the mesothelioma cases $(\mathrm{n}=34)$ occurring during 1979-94 can be attributed to environmental exposure to town residents or visitors. ${ }^{35}$ Epidemiological studies of environmental exposure to asbestos in Turkey have revealed a high incidence of asbestos related diseases including pleural plaque, chronic fibrosing pleuritis, and mesothelioma among peasants from several villages. Similar to peasants in Da-yao, these villagers from Turkey used soil mixed with asbestos as white stucco for plastering their houses and paving the roads. The types of asbestos encountered in these Turkish villages are mainly chrysotile, tremolite, actinolite, and anthophyllite.

Although the commercial use of asbestos in Da-yao has been banned since 1984, the incidence of mesothelioma has continued to show a large increase. Since the latency of mesothelioma is approximately $30-40$ years, the ban had little effect in the 1990s. In addition, daily inhalation of asbestos fibres from dusty farm roads not only continued, but was also aggravated by the increasing number of speeding motor vehicles that left a cloud of dust behind them for the

\section{Policy implications}

- As a result of our effort in identifying and quantifying the health risk of asbestos in this community, several public health interventions have been implemented by the government; for example, asbestos stove production was officially banned in 1984, other types of stoves gradually replaced stoves made of asbestos clay, the health hazards of asbestos fibres were widely dissimilated throughout the county, and local government has improved dirt roads and covered many with tar pitch or cement.

- Due to financial constraints of the county/province and the long latency of cancer caused by asbestos, the reduction of asbestos related medical conditions has not been as expeditious as one might hope.

schoolchildren and walking peasants to breathe. Furthermore, the peeling walls painted with blue clay and the disintegrating asbestos stoves or stove tubes could both send asbestos fibres into the air when exposed to moving air.

Several public health interventions have been implemented. As a result of our effort in identifying and quantifying the health risk of asbestos in this community, the asbestos stove production was officially banned in 1984. Gas stoves gradually replaced stoves made of asbestos clay. The health hazards of asbestos fibres were widely dissimilated throughout the county and province. The local government has improved dirt roads and covered many with tar pitch or cement. However, because of the financial and economic constraints of the county/province, the progress has not been as expeditious as one might hope. In a recent visit to Da-yao (October 1999) by three of the authors (SL, SPT, and CPW), it was noted that the family style commercial production of asbestos stoves has almost ceased except for one small operation with a stockpile of stoves waiting to be sold. Therefore, the exposure from crushing crocidolite rocks in stove making has become minimal or negligible. However, rocks containing crocidolite fibres are seen and used everywhere, most notably to pave and maintain the farm roads. The dust level invariably reached a suffocating concentration when vehicles passed by. Large lumps of crocidolite rock were used as building materials for fencing (for example, pig pens, vegetable gardens, and houses). The peeling walls were both an eyesore and a health hazard. The irrigation and drinking water came from reservoirs or lakes that were levelled with crocidolite containing soil. The drinking water is both aesthetically unappealing and hygienically unacceptable. However, to these peasants struggling in poverty, the health risk from asbestos exposure seems to rank as one of their lower concerns. Those people who are stricken with asbestos related diseases quickly give up seeking medical treatment when they realise that they cannot afford the expensive diagnostic work up. Another reality, spread by word of mouth based on their own observation, is that for most asbestos related diseases, even if they underwent all recommended treatment and experienced major physical suffering, the outcome was no better.

Having been exposed environmentally to crocidolite asbestos since birth, this population is unique and provides a good opportunity to quantify the adverse health effects in a large population at a relatively low level of exposure. The available sample size is sufficiently large to construct a new risk assessment model based on chest $x$ ray findings (for example, pleural plaques or asbestosis) and mesothelioma/lung cancer cases. The establishment of a mesothelioma panel to verify cases, an exposure panel to assess the intensity, duration, and frequency of previous personal exposures, and a cancer registry to record all new cases would greatly facilitate the future conduct of a longitudinal cohort study and risk assessment. However, an urgent and obvious need remains either to pave all the farm roads in Da-yao or to provide an ample quantity of 
non-asbestos containing rocks for replacing the local ones. Any academic research proposal should include such a regimen for remedying the continuing health threat to the residents.

\section{Authors' affiliations}

S Luo, X Liu, S Mu, S P Tsai, C P Wen, Department of Occupational Health, School of Public Health, West China University of Medical

Sciences, Chengdu, Sichuan, China

\section{REFERENCES}

1 Yang G, Fan L, Tan J, et al. Smoking in China: findings of the 1996 National Prevalence Survey. JAMA 1999;282:1247-53.

2 Liu X, Luo S, Wang Z, et al. Crocidolite contamination and mesothelioma [in Chinese]. Chin J Ind Hyg Occup Dis 1988;6:193-7.

3 Liu X, Luo S, Wang Z, et al. An investigation of crocidolite contamination and mesothelioma in a rural area of China. Biomed Environ Sci 1990;3:156-65.

4 Liu X, Luo S, Wang C. The carcinogenicity of several species of asbestos produced in China. Biomed Environ Sci 1990;3:373-7.

5 Luo S, Mu S, Zhan C, et al. A retrospective cohort study (1987-1995) of malignant neoplasm in a county contaminated with crocidolite [in Chinese]. Chin J Ind Hyg Occup Dis 1997;15:272-76.

6 Zhou Y, Luo S, Song Y, et al. A clinical-pathologic analysis of 47 cases of mesothelioma resulted from environmental exposure to crocidolite [in Chinese]. Chin J Ind Hyg Occup Dis 1998;16:169-70.

7 Mu S, Luo S, Yang H, et al. A retrospective cohort study on the mortality of rural area in Da-yao county [in Chinese]. Modern Prev Med 1998;25:63-5.

8 Jolicoeur CR, Alary JF, Sokov A. Asbestos. In: Kroschwitz JI, Howe-Grant M, eds. Encyclopedia of chemical technology. New York: John Wiley \& Sons, 1991:659-88.

9 Asbestos International Association. Reference method for the determination of airborne asbestos fiber concentrations at workplace by light microscopy. London: Asbestos International Association, 1979.

10 ACGIH. Threshold limit values and biological exposure indices for 1989-1990. American Conference of Governmental Industrial Hygienists, Cincinnati, OH, 1989.

11 Hillerdal G. Mesothelioma: cases associated with non-occupational and low dose exposures. Occup Environ Med 1999;56:505-13.

12 Department of Health, People's Republic of China. Compendium data from nationwide epidemiological survey of pneumoconiosis, 1949-1986 [in Chinese]. Beijing: United Publishing Company of Beijing Medical College and Chinese Union Medical College, 1992

13 IARC. Monographs on the evaluation of carcinogenic risks to human. Supplement 7. Lyon, France: IARC, 1987.

14 Doll R. Mortality from lung cancer in asbestos workers. Br J Ind Med 1955; 12:81-7.

15 Becklake MR. Asbestos-related diseases of lung and other organs: their epidemiology and implications for clinical practice. Am Rev Respir Dis 1976:114:187-227.

16 Selikoff IJ, Lee HR. Asbestos and disease. San Diego: Academic Press, 1978

17 Selikoff IJ, Hammond EC, Seidman H. Mortality experience of insulation workers in the United States and Canada, 1943-1976. Ann N Y Acad Sci 1979:330:91-116

18 Selikoff IJ, Lilis R, Nicholson WJ. Asbestos disease in United States shipyards. Ann N Y Acad Sci 1979;330:295-311.

19 Enterline PE, Henderson V. Type of asbestos and respiratory cancers in the asbestos industry. Arch Environ Health 1973;27:312-17.

20 McDonald JC, McDonald AD. The epidemiology of mesothelioma in historical context. Eur Respir J 1996;9:1932-42.

21 Morgan RW, Foliant DE, Wong O. Asbestos and gastrointestinal cancer-a review of the literature. West J Med 1985;143:60-5.

22 Hodgson JT, Jones RD. Mortality of asbestos workers in England and Wales 1971-80. Br J Ind Med 1986:43:158-65.

23 Landrigan PJ. Asbestos-still a carcinogen. N Engl J Med 1988;338:1618-19

24 Blot WJ, Fraumeni JF. Cancers of the lung and pleura. In: Schottenfeld D, Fraumeni JF, eds. Cancer epidemiology and prevention. New York: Oxford University Press, 1996:637-65.

25 Luo S, Liu X, Wang C. An investigation of crocidolite contamination and experimental study in southwestern China. J Hyg Epidemiol Microbiol Immunol 1992;36:223-4.

26 Ministry of Health and Welfare, Japan. Vital statistics, vol. 3, 1987, 1991, 1997. Statistics and Information Department, Minister's Secretariat; Ministry of Health, Japan, 1987, 1991, 1997.

27 Morinaga K, Sakatani M, Kishimoto T, et al. Epidemiology of asbestos related diseases and its preventive measures in Japan. In: Proceedings of the First China-Japan Joint Asbestos Symposium. Ministry of Health, People's Republic of China, Japan China Medical Association, Institute of Occupational Medicine, Chinese Academy of Preventive Medicine and Japan Asbestos Hazards Stud Group, Beijing, China 16-17 July 1999.

28 Health and Vital Statistics, Republic of China. Health and vital statistics, 2 [in Chinese]. Vital Statistics, Republic of China, 1997. Department of Health, the Executive Yuan, Republic of China, 1998.
29 Hillerdal, G. Diagnosis of asbestos-related diseases and its future incidence in the developing and industrialized countries. In: Proceedings of the First China-Japan Joint Asbestos Symposium. Ministry of Health, People's Republic of China, Japan China Medical Association, Institute of Occupational Medicine, Chinese Academy of Preventive Medicine and Japan Asbestos Hazards Study Group, Beijing, China, 16-17 July 1999.

30 Peto J. Dose-response relationships for asbestos-related disease: implications for hygiene standards-Part II. Mortality. Ann N Y Acad Sci 1979;330: 195-203.

31 Irwig LM, duToit RSJ, Sluis-Cremer GK, et al. Risk of asbestosis in crocidolite and amosite mines in South Africa. Ann N Y Acad Sci 1979:330:35-52.

32 Hugh JM, Weill H. Asbestos exposure-quantitative assessment of risk. Am Rev Respir Dis 1986;133:5-13.

33 Wagner JC, Steggs CA, Marchand P. Diffuse pleural mesothelioma and asbestos exposure in northwestern Cape Province. Br J Ind Med 1960;17:260-71

34 Botha JL, Irwig LM, Strebel PM. Excess mortality from stomach cancer lung cancer and asbestosis and/or mesothelioma in crocidolite mining districts in South Africa. Am J Epidemiol 1986;123:30-40.

35 Rogers A, Nevill M. Occupational and environmental mesothelioma due to crocidolite mining activities in Wittenoom, Western Australia. Scand J Work Environ Health 1995;21:259-64.

36 Baris YI, Artvinli M, Sahin A. Environmental mesothelioma in Turkey. Ann N Y Acad Sci 1979;330:91-116.

\section{COMMENTARY}

In a landmark paper published in 1960 in the then British Journal of Industrial Medicine, Wagner et al reported 33 cases of diffuse mesothelioma among residents living near crocidolite mines in Cape Providence, South Africa. ${ }^{1}$ Although the Wagner et al report was not an analytical epidemiological study and no risk estimate was calculated, the large number of cases and the rarity of the cancer provided strong evidence for an association between crocidolite and diffuse mesothelioma. Another well known example of mesothelioma excess resulting from environmental exposure is that among residents of Karain, a small village in the Anatolia region of Turkey. ${ }^{23}$ Pleural or peritoneal mesothelioma accounted for $40-50 \%$ of all deaths in Karain. The culprit was erionite (a fibrous zeolite mineral), which occurred naturally throughout the region and was used by local villagers as building blocks and plaster for houses.

Luo et al report excesses of mesothelioma and other asbestos related diseases among residents in three villages in Da-yao, a rural county in southwest China. Their paper consists of a cross sectional health survey, pathological analyses, and three cohort studies of area residents. The Da-yao area is covered with topsoil rich in crocidolite ore ("blue clay"). Chemically, the principal compositions of Da-yao crocidolite were quite similar to crocidolite mined in South Africa, but different from chrysotile mined in Quebec. Physically, the Da-yao fibres are characterised by high aspect ratios. Due to weathering and surface erosion, the villages are contaminated with crocidolite fibres, and residents are constantly exposed to asbestos containing clay dust. Additionally, the blue clay was used as building blocks and plaster for houses, and in filling potholes on roads and streets. The material was also used in making stoves, which were sold locally and elsewhere. Increased risks of mesothelioma, lung cancer, and pleural plaque were reported among the villagers. In the cohort studies, mesothelioma deaths accounted for $2-3 \%$ of all deaths in Da-yao, which by comparison was much lower than the risks reported from South Africa or Turkey. Although the results of the Da-yao investigations have previously been reported in Chinese medical journals, the Luo et al paper serves to document in an international journal the serious health effects of environmental contamination of crocidolite in Da-yao.

Several aspects of the investigations in Da-yao, however, need to be pointed out; including the lack of adequate comparison rates of mesothelioma in unexposed individuals, the lack of centralised systematic follow up, the high percentage of unknown vital status ( $10 \%$ in the first cohort study), 
the high percentage of unknown causes of death $(16 \%$ and $25 \%$ in the second and third studies), the high rate of unconfirmed mesothelioma cases, and the use of crude mortality rates in cohort analysis. Unfortunately, given the resources and circumstances in which the investigations were carried out, most of these limitations were unavoidable. These potential limitations, however, do not invalidate the main finding of the investigations - that residents in Da-yao experienced significant increases of mesothelioma and other asbestos related diseases.

Luo et al proposed the establishment of pathological review and exposure assessment panels and additional investigations. From the scientific point of view, suggestions to further our knowledge are always welcome. From the public health perspective, however, the most important issue is the avoidance of further exposure. Exposed surfaces of roads and streets should be paved and asbestos stoves should be banned and recalled. Serious public health efforts and resources must be immediately directed to educating residents of the dangers of continuing exposure.

Otto Wong

Applied Health Sciences, Inc., 181 Second Avenue, Suite 628, San Mateo, California 94010, USA; ottowong@aol.com

\section{REFERENCES}

1 Wagner JC, Sleggs CA, Marchand P. Diffuse pleural mesothelioma and asbestos exposure in the north western Cape Province. Br J Ind Med 1960:17:269-71.

2 Baris YI, Artvinli MA, Sahin AA. Environmental mesothelioma in Turkey. Ann N Y Acad Sci 1979;330:423-32.

3 Baris YI. Fibrous zeolite (erionite)-related diseases in Turkey. Am J Ind Med 1991;19:374-8.

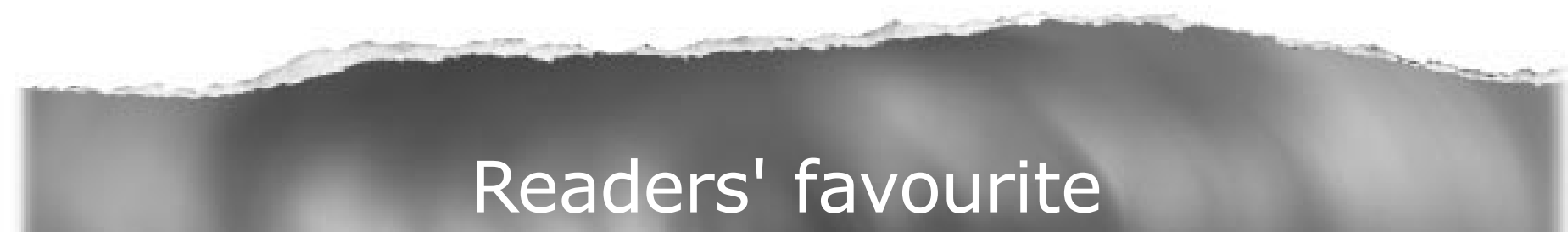

Top 10

Click on the "Top 10" button on the homepage to see which are the best read articles each month

www.occenvmed.com 